\title{
3-Chloropropionyl Chloride
}

\section{Magdalena Grabkowska-Drużyc}

Bioorganic Chemistry Laboratory, Faculty of Pharmacy Medical University of Lodz, Muszyńskiego 1, 90-151 Lodz, Poland

magdalena.grabkowska-druzyc@umed.lodz.pl

Published online: 23.07.2015

DOI: 10.1055/s-0034-1381100; Art ID: st-2015-v0521-v

\section{Introduction}

Acyl chlorides are highly reactive derivatives of carboxylic acids and therefore are applied widely in acylations. 3-Chloropropionyl chloride is an important bifunctional reagent. It is capable of acylation and possesses a 2-chloroethyl fragment $\left(\mathrm{CH}_{2} \mathrm{CH}_{2} \mathrm{Cl}\right)$, which can be subjected to nucleophilic substitution and serves as a masked vinyl group. It can be used as a starting material in many reactions to construct a variety of (hetero)cyclic compounds.

\section{Preparation}

3-Chloropropionyl chloride (1) is commercially available and can be prepared from $\beta$-propiolactone (2) and thionyl chloride. ${ }^{1}$ Other standard methods available for the
Magdalena Grabkowska-Drużyc was born in Starachowice (Poland) in 1985. She received her M.Sc. in chemistry in 2009 working in the group of Professor Grzegorz Mlostoń at the University of Lodz (Poland). She has been employed as a Teaching Assistant at the Bioorganic Chemistry Laboratory, Faculty of Pharmacy, Medical University of Lodz since 2010 under the guidance of Dr. Dorota G. Piotrowska. Her research interests focus on the synthesis of new isoxazolidine analogues of $\mathrm{C}$-nucleotides of the potential anticancer and antiviral activity.

preparation of acyl chlorides can also be applied: the reaction of acrylic acid (3) or 3-chloropropionic acid (4) with thionyl chloride, phosphoryl chloride, phosgene, or phosphorus trichloride.
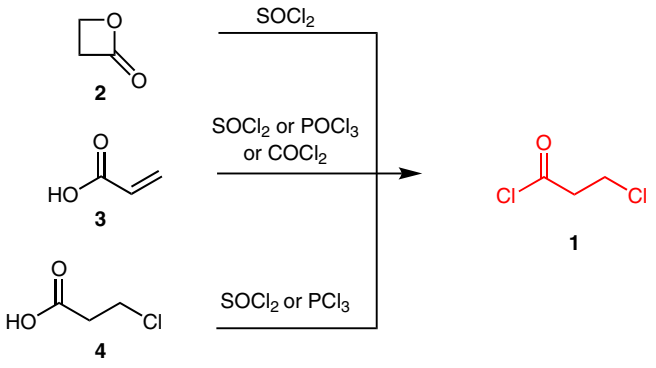

Scheme 1

Table 1 Use of 3-chloropropionyl chloride

(A) The Friedel-Crafts acylation of tert-butylbenzene (5) with 3-chloropropionyl chloride (1) followed by cyclization provided indanone $\mathbf{6}$, which was further transformed into urea derivative 7, a potent TRPV1 antagonist. ${ }^{2}$

(1)

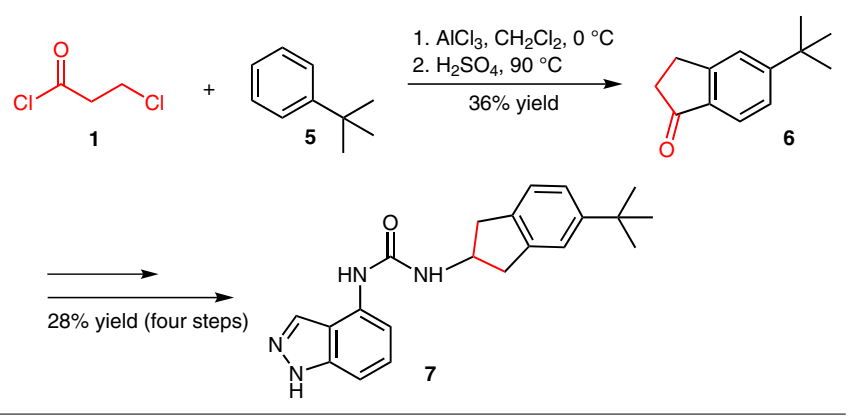

(B) A novel high-yielding one-pot microwave-assisted synthesis of condensed 5-substituted pyranoisoquinoline-1,6-diones 9 from 2-substituted isoquinoline-1,3-diones 8 and 3-chloropropionyl chloride (1) was reported. ${ }^{3}$

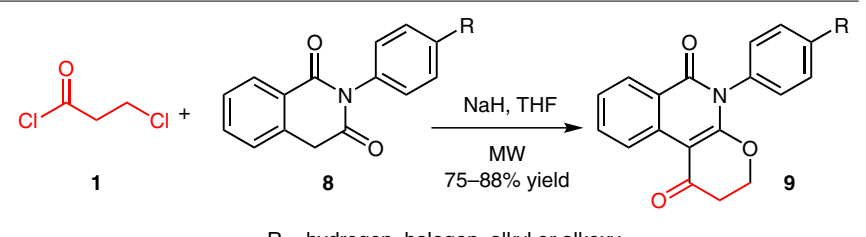

$\mathrm{R}=$ hydrogen, halogen, alkyl or alkoxy

(C) Aouf et al. reported the titanium tetrachloride mediated addition of 3-chloropropionyl chloride (1) to 2,3,6,7-tetramethyl-1,8bis(trimethylsilyl)-octa-2,6-diene (10) leading to cyclopentanol derivative 11, which contains three quaternary carbons. ${ }^{4}$

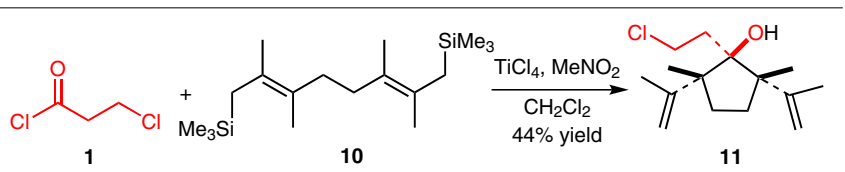


(D) Acylation of 2-aminophenol (12) with 3-chloropropionyl chloride (1), followed by cyclization in the presence of polyphosphoric acid (PPA), gave benzoxazole 13, which was further reacted with 4-chlorophenyl-1-piperazine to yield the target benzo[d]oxazole analogue $\mathbf{1 4}$, a selective dopamine $\mathrm{D}_{4}$ receptor ligand. ${ }^{5}$

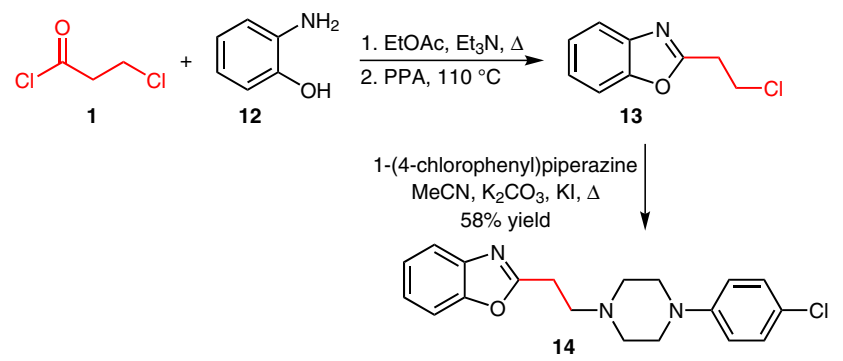

(E) Acylation of substituted nitriles $\mathbf{1 5}$ with 3-chloropropionyl chloride (1) and subsequent intramolecular cyclization afforded 2-aryl2-pyrrolidinecarbonitriles $\mathbf{1 6}$ which were subsequently hydrolysed to 2-aryl-2-pyrrolidinecarboxamides $\mathbf{1 7}$, showing moderate anticancer activity. ${ }^{6}$

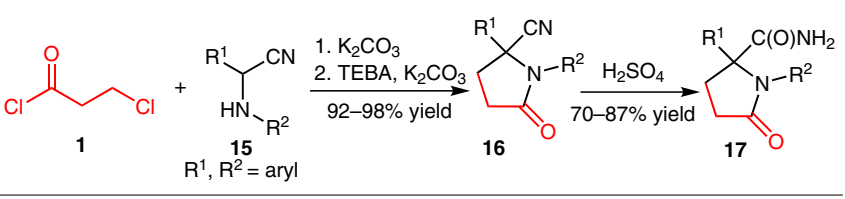

(F) 3-Chloropropionyl chloride (1) was applied in the preparation of intermediate $\mathbf{1 9}$ in the synthesis of cephalotaxine (20). The $\gamma$-lactam ring in $\mathbf{1 9}$ was constructed in a two-step sequence involving $\mathrm{N}-$ acylation and intramolecular alkylation. ${ }^{7}$

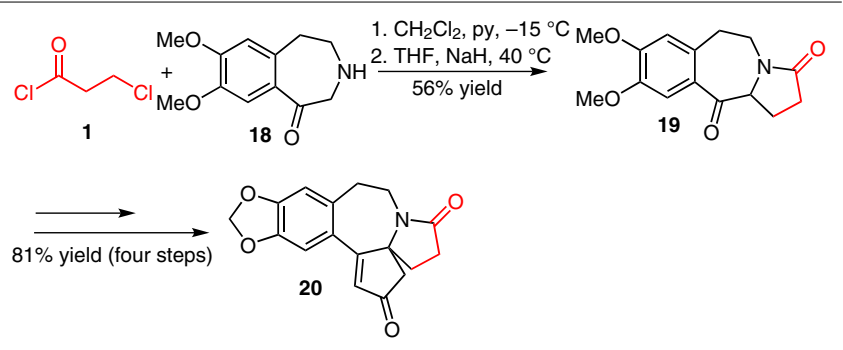

(G) Ozcan et al. reported the synthesis of oxadiazoloisopropylamide 23 as potent and noncovalent proteasome inhibitor. O-Acylation of $\mathrm{N}$-hydroxyamidine 21 with 3-chloropropionyl chloride (1) and subsequent intramolecular cyclization afforded the intermediate oxadiazole 22, which was further transformed into $\mathbf{2 3}$ in good yield. ${ }^{8}$

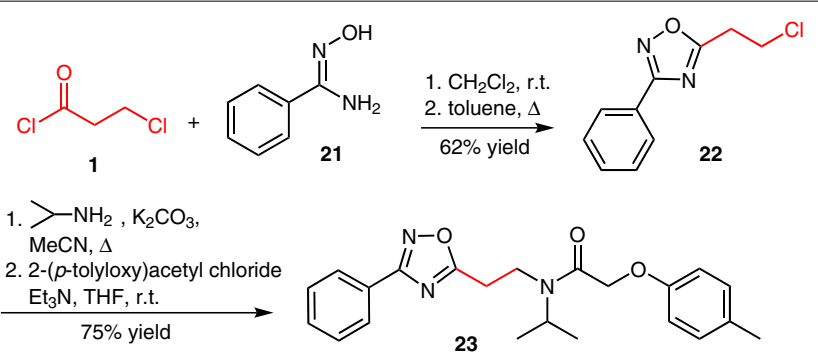

(H) The synthesis of 2-imidazolidinones $\mathbf{2 5}$ and $\mathbf{2 6}$ (potential TACE inhibitors) started with the preparation of an unstable isocyanate $\mathbf{2 4}$ by reacting 3 -chloropropionyl chloride (1) with sodium azide. ${ }^{9}$

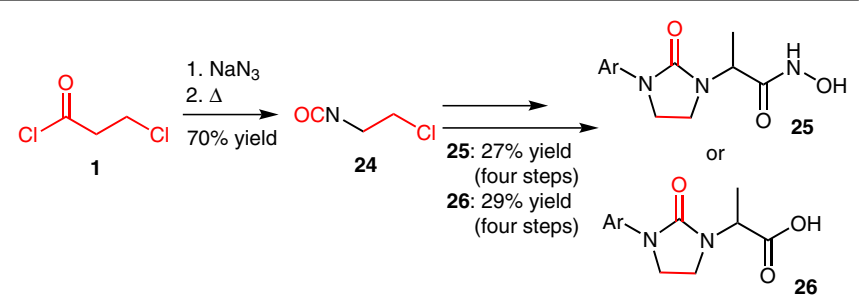

\section{References}

(1) Gresham, T. L.; Jansen, J. E.; Shaver, F. W. J. Am. Chem. Soc. 1950, $72,72$.

(2) Gomtsyan, A.; Bayburt, E. K.; Schmidt, R. G.; Surowy, C. S.; Honore, P.; Marsh, K. C.; Hannick, S. M.; McDonald, H. A.; Wetter, J. M.; Sullivan, J. P.; Jarvis, M. F.; Faltynek, C. R.; Lee, C.-H. J. Med. Chem. 2008, 51, 392.

(3) Havaldar, F. H.; Mule, G. B.; Dabholkar, B. V. J. Heterocycl. Chem. 2013, 50, 828.

(4) Aouf, C.; Abed, D. E.; Ibrahim-Ouali, M.; Giorgi, M.; Santelli, M. Eur. J. Org. Chem. 2007, 19, 3115.
(5) Sampson, D.; Zhu, X. Y.; Eyunni, S. V. K.; Etukala, J. R.; Ofori, E.; Bricker, B.; Lamango, N. S.; Setola, V.; Roth, B. L.; Ablordeppey, S. Y. Bioorg. Med. Chem. 2014, 22, 3105.

(6) Gasparyan, S. P.; Alexanyan, M. V.; Arutyunyan, G. K.; Oganesyan, V. E.; Martirosyan, V.; Paronikyan, R. V.; Stepanyan, G. M.; Martirosyan, A. O. Pharm. Chem. J. 2012, 46, 331.

(7) Zhang, Z.-W.; Zhang, X.-F.; Feng, J.; Yang, Y.-H.; Wang, C.-C.; Feng, J.-C.; Liu, S. J. Org. Chem. 2013, 78, 786.

(8) Ozcan, S.; Kazi, A.; Marsilio, F.; Fang, B.; Guida, W. C.; Koomen, J.; Lawrence, H. R.; Sebti, S. M. J. Med. Chem. 2013, 56, 3783.

(9) DasGupta, S.; Murumkar, P. R.; Giridhar, R.; Yadav, M. R. Bioorg. Med. Chem. 2009, 17, 3604. 